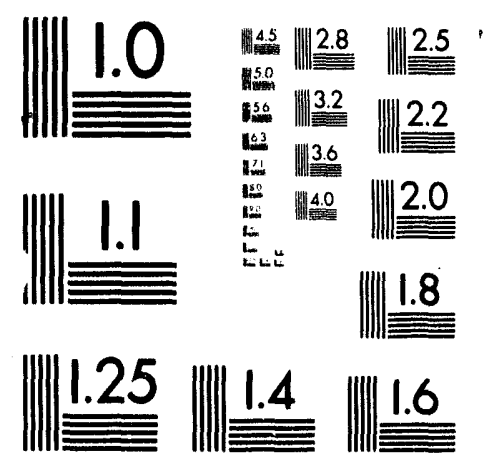



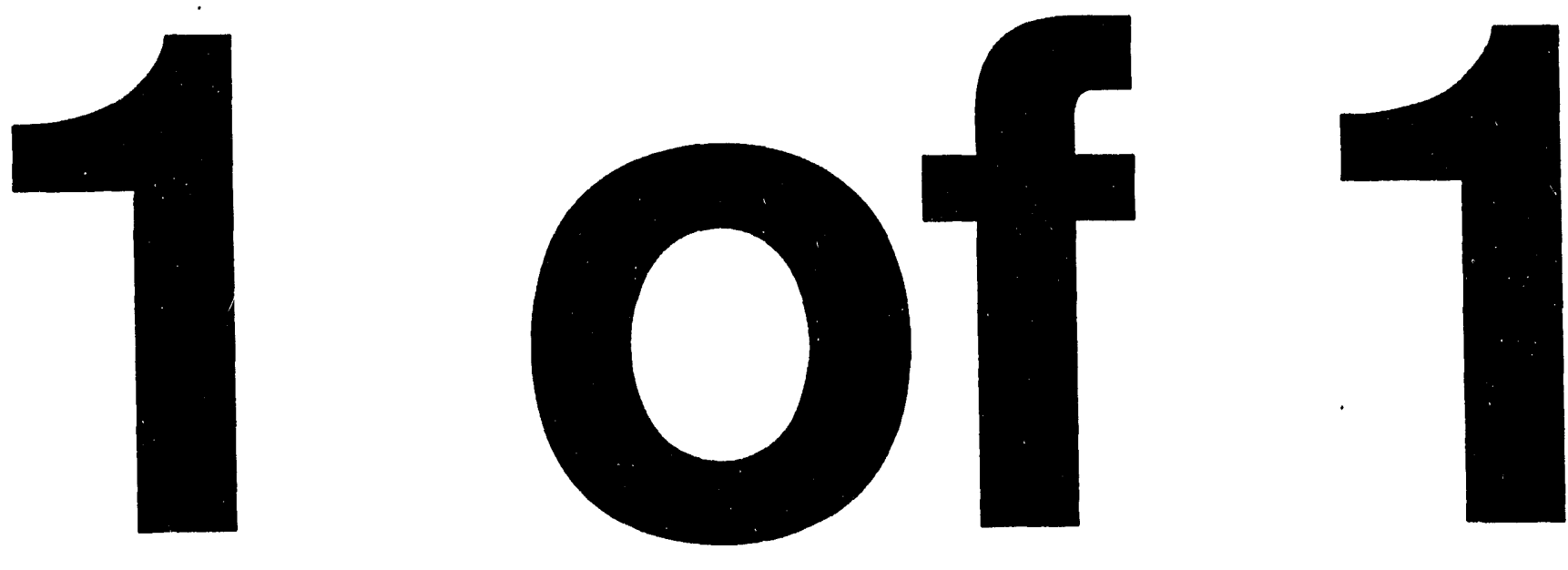


\section{Preliminary Detector Design ST862-Prototype Neutron Detector}
S. D. Miller
J. D. Affinito
D. R. Sisk

December 1993

Prepared for the U.S. Department of Energy under Contract DE-AC06-76RLO 1830

Pacific Northwest Laboratory

Operated for the U.S. Department of Energy

by Battelle Memorial Institute 


\title{
DISCLAIMER
}

This report was prepared as an account of work sponsored by an agency of the United States Government. Neither the United States Government nor any agency. thereof, nor Battelle Memorial Institute, nor any of their employees, makes any warranty, expressed or implied, or assumes any legal liability or responsibility for the accuracy, completeness, or usefulness of any information, apparatus, product, or process disclosed, or represents that its use would not infringe privately owned rights. Reference herein to any specific commercial product, process, or service by trade name, trademark, manufacturer, or otherwise does not necessarily constitute or imply its endorsement, recommendation, or favoring by the United States Government or any agency thereof, or Battelle Memorial Institute. The views and opinions of authors expressed herein do not necessarily state or reflect those of the United States Government or any agency thereof.

\author{
PACIFIC NORTHWEST LABORATORY \\ operated by \\ BATTELLE MEMORIAL INSTITUTE \\ for the \\ UNITED STATES DEPARTMENT OF ENERGY \\ under Contract DE-AC06-76RLO 1830
}

Printed in the United States of America

Available to DOE and DOE contractors from the

Office of Scientific and Technical Information, P.O. Box 62, Oak Ridge, TN 37831; prices available from (615) 576-8401. FTS 626-8401.

Available to the public from the National Technical Information Service, U.S. Department of Commerce, 5285 Port Royal Rd., Springfield, VA 22161. 
PRELIMINARY DETECTOR DESIGN ST862-

PROTOTYPE NEUTRON DETECTOR
S. D. Miller
J. D. Affinito
D. R. Sisk

December 1993

Prêpared for

the U.S. Department of Energy

under Contract DE-AC06-76RLO 1830

Pacific Northwest Laboratory

Richland, Washington 99352 


\section{SUMMARY}

The detection of fast neutrons has been accomplished with commercially available liquid scintillators in detectors. Liquid scintillators discriminate fast neutrons from gamma radiation by discarding pulses with short decay constants. However, pulse-timing methods require expensive, bulky equipment and a high degree of technical sophistication in the user. Researchers at Pacific Northwest Laboratory have developed a new class of scintillating material, polymerizing crystals of $\mathrm{CaF}_{2}(\mathrm{Eu})$ and liquid acrylate monomers with matched indexes of refraction. The new detectors avoid the pulse-timing methods of liquid detectors and allow detectors to be large and relatively light. Fast neutrons can be discriminated from gamma radiation solely on the basis of pulse height (i.e., energy deposition). Using these detectors, a hand-held neutron detection instrument is proposed that can operate on battery power for 8 to 12 hours and be easily used in field conditions for surveying vehicles and structures. 


\section{CONTENTS}

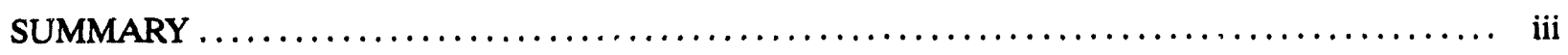

INTRODUCTION $\ldots \ldots \ldots \ldots \ldots \ldots \ldots \ldots \ldots \ldots \ldots \ldots \ldots \ldots \ldots \ldots \ldots \ldots \ldots \ldots \ldots \ldots \ldots \ldots \ldots, 1$

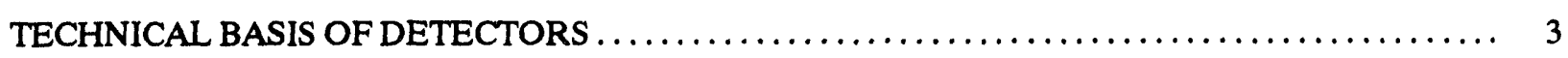

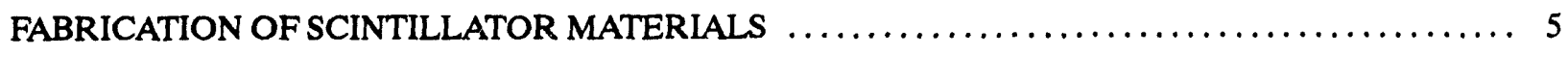

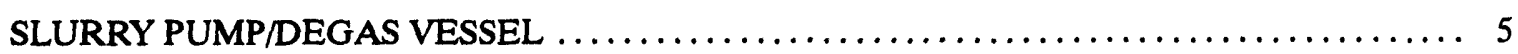

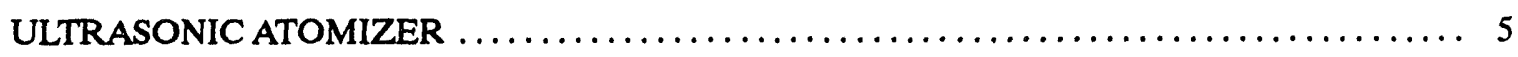

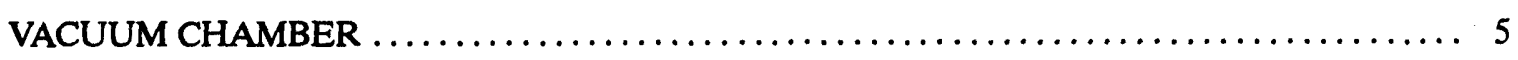

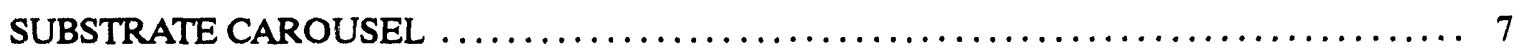

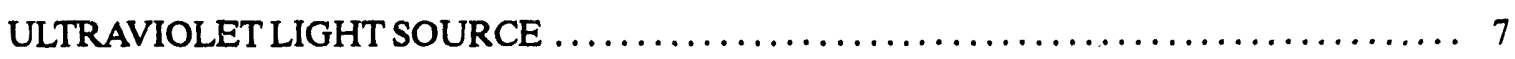

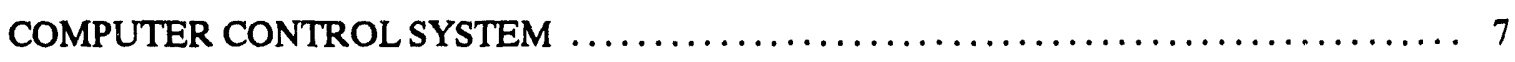

DESCRIPTION OF PROTOTYPE FAST NEUTRON DETECTION INSTRUMENT $\ldots \ldots \ldots \ldots \ldots 9$ 


\section{FIGURES}

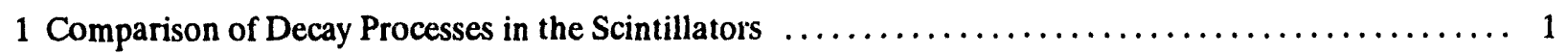

2 Pulse-height Discrimination Between Neutron and Gamma Events $\ldots \ldots \ldots \ldots \ldots \ldots \ldots \ldots \ldots$

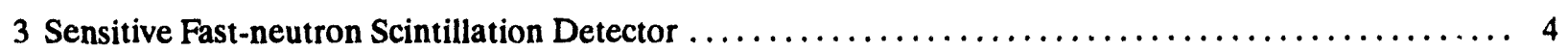

4 Thin-layer Detector Fabricated from Refractive-Index-Matched

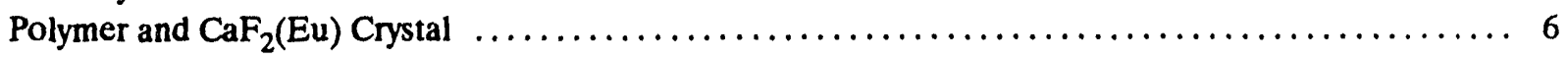

5 Automated Detector Fabrication Station $\ldots \ldots \ldots \ldots \ldots \ldots \ldots \ldots \ldots \ldots \ldots \ldots \ldots \ldots \ldots \ldots$

6 Scintillator Applications (ST862) Prototype Neutron Detector $\ldots \ldots \ldots \ldots \ldots \ldots \ldots \ldots \ldots \ldots$

7 Scintillator Applications (ST862) Prototype Detector Hand-held

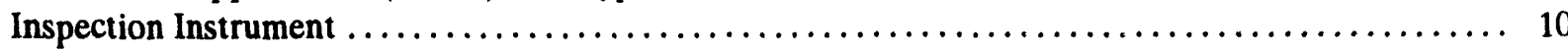




\section{INTRODUCTION}

The detection of fast neutrons has been done in the past using commercially available liquid scintillators in detectors, such as NE-213. To discriminate fast neutrons from gamma rays, liquid scintillators use pulsetiming. Densely ionizing particles, such as fast neutrons and alpha particles, exhibit a longer-decay process than do gamma rays (see Figure 1). The liquid scintillator detectors discriminate fast neutrons from gamma radiation by discarding those pulses with short decay constants. Pulse-timing requires expensive, bulky electronics in the instruments and a high degree of sophistication in the user. Unfortunately, pulse-timing methods are absolutely essential in this type of instrument because of the liquid scintillators, which have efficiencies approximately 10 times greater for gamma rays as for fast neutrons of equivalent energies.

Thus, there has been a need for a type of scintillator that is more sensitive to fast neutrons and is easier to build into a detector and to use in field conditions. Work at the Pacific Northwest Laboratory (PNL) ${ }^{(a)}$ has resulted in the production of a more stable scintillator made from inorganic salts that may prove to be easier to use in instrumentation than liquid scintillators, while making it easier to discriminate fast neutron from gamma radiation.

This report explains the technical basis for the ne'N detectors being developed at PNL, describes the fabrication process now used for making large fast-neutron detectors, and describes a prototype instrument that uses the new detectors.

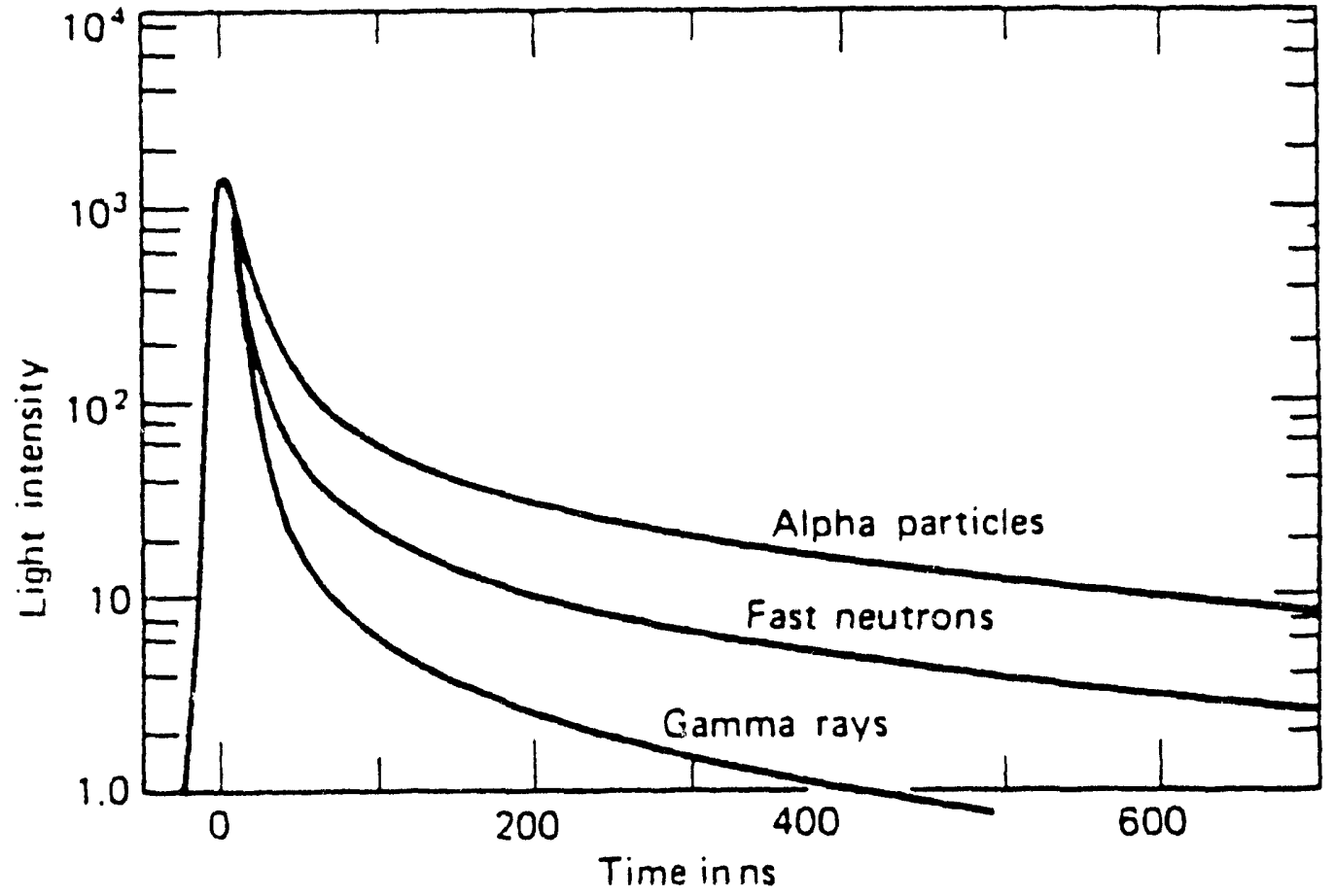

Figure 1. Comparison of Decay Processes in the Scintillators

(a) The Pacific Northwest Laboratory operated for the U.S. Department of Energy by Battelle Memorial Institute under Contract DE-AC06-76RLO 1830. 


\section{TECHNICAL BASIS OF DETECTORS}

In developing a new class of scintillating materials, differences in the ways gamma and proton-recoil fast neutrons deposit their energies in the same material have been used. Neutron-induced proton recoils deposit their energy within very small volumes compared to gamma rays of similar energy, as Figure 2 illustrates. A fast neutron detector, it was reasoned, could be built by incorporating very small grains of scintillator within an optically transparent hydrogen-rich matrix (see Figure 3).

The optimal size of scintillator grains was determined by the range of the most energetic proton recoils.

Inorganic scintillators appear to be best for fast neutrons because of their superior responsibilities and sensitivity to charged particles and their larger overall scintillation efficiency compared to organic scintillators. With higher efficiency scintillators, instruments could use less complicated and less bulky detectors in their designs, i.e., using photodiodes rather than photomultiplier tubes.

To minimize light scattering within the detector, single crystal scintillators can be matched to the plastic matrix by their index of refraction. Thus matched, the scintillators and the plastic matrix could perform efficiently in large-size detectors.

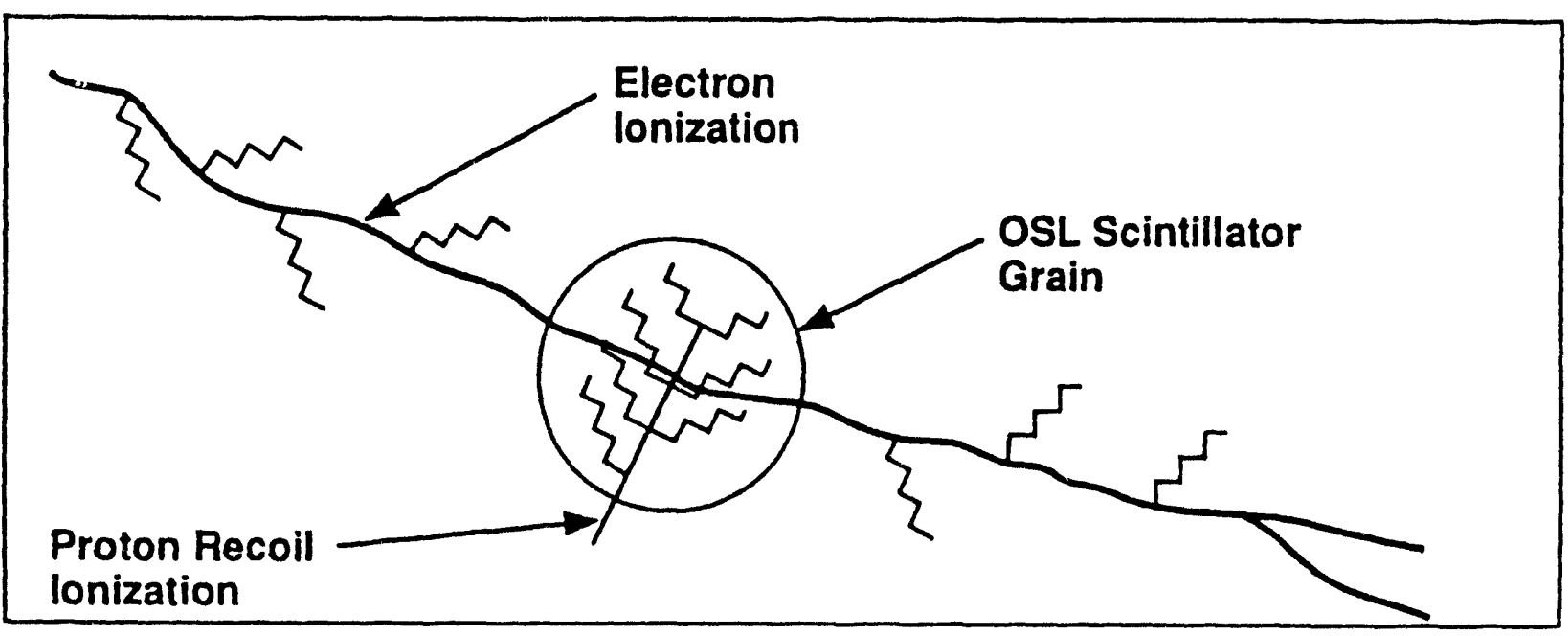

Figure 2. Pulse-height Discrimination Between Neutron and Gamma Events 


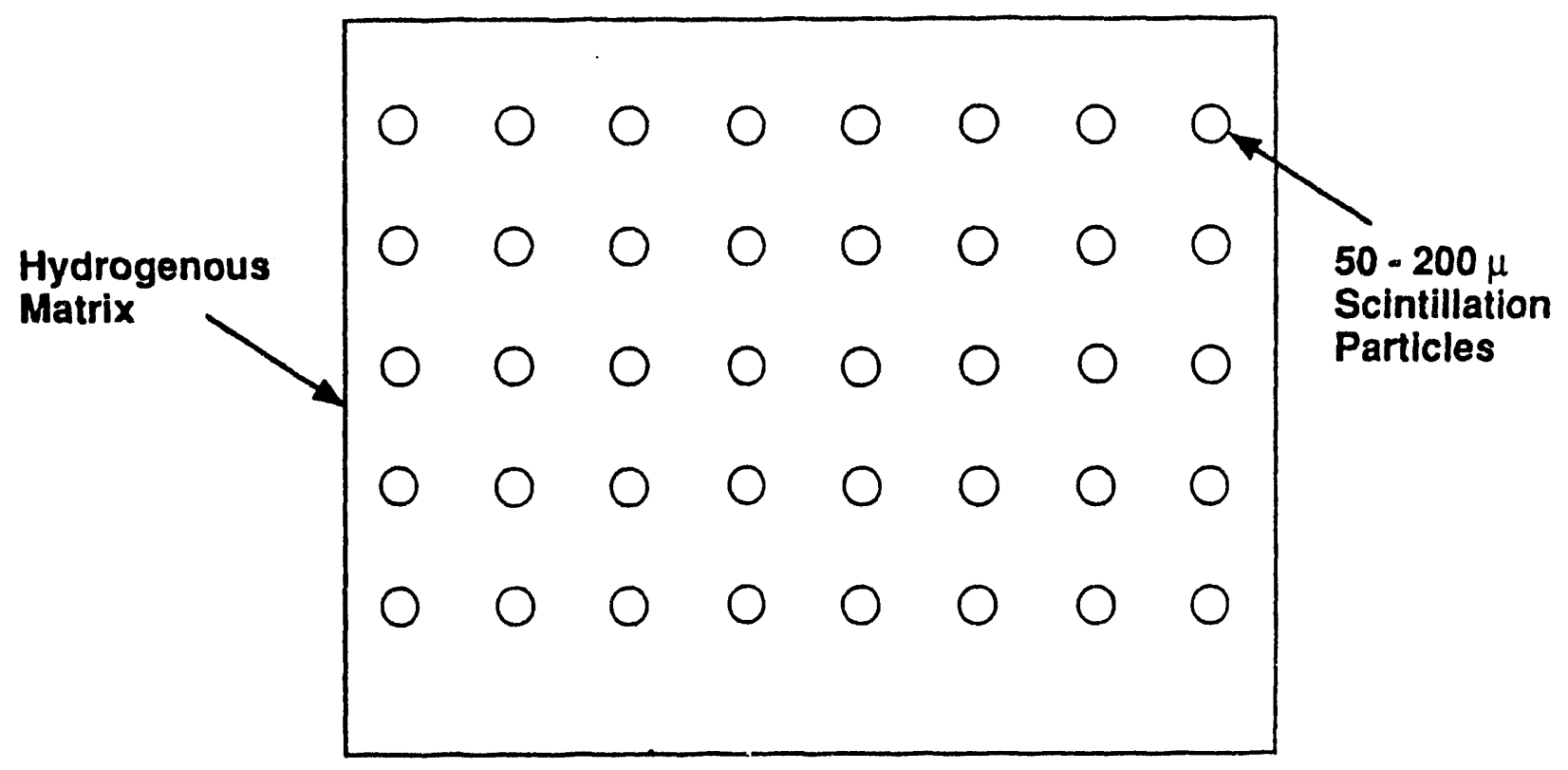

Figure 3. Sensitive Fast-neutron Scintillation Detector

4 


\section{FABRICATION OF SCINTILLATOR MATERIALS}

An automated fabrication station was constructed to produce a prototype of the required refractiveindex-matched polymer/crystal composite scintillators, approximately 2 in. in diameter and $1 \mathrm{in.} \mathrm{thick.} \mathrm{To}$ eliminate scattering at the interface, intimate contact is required between crystal and polymer, along with a correct index match; otherwise, the voids and gaps will scatter the energy. The crystal material used was $\mathrm{CaF}_{2}(\mathrm{Eu})$ with refractive index 1.43 . The polymer matrix was a mixture of two acrylate with refractive indices of 1.35 and 1.55. To achieve the required intimate contact between crystal and polymer, slurries of liquid acrylate monomers and $\mathrm{CaF}_{2}(\mathrm{Eu})$ were polymerized (as opposed to mixing solids together). Since a detector of the desired thickness could not be polymerized without the crystals failing from suspension, the devices were fabricated as hundreds of layers - each about the thickness of the crysials (several mils). In order to get the proper substrate, layer-to-layer wetting, and a smooth surface, the dispense-and-cure operation had to be under vacuum, where surface tension conditions were more favorable. Figure 4 shows a completed detector on both sides.

The fabricating station consisted of six basic sub-systems: a vacuum chamber; a substrate carousel within the vacuum chamber; a combination monomer slurry pump/degas vessel to remove atmospheric gas prior to injection into the vacuum; an ultrasonic atomizer to dispense the monomer/crystal slurry; an ultraviolet light source to cure the monomer/crystal slurry; and a computer control system. Figure 5 shows the fabricating station and computer control.

\section{SLURRY PUMP/DEGAS VESSEL}

The slurry pump/degas vessel is a piston-type syringe pump. The cylinder is filled with the monomer/crystal mixture. The crystals are kept suspended by a magnetic stirring bar in the cylinder and a rotating magnetic field external to the cylinder. The syringe is pumped via air pressure on the plunger. The piston requires a 0.010 -in. gap, or larger, to the cylinder wall to prevent shear polymerization of the monomer in the cylinder.

\section{ULTRASONIC ATOMIZER}

The syringe pump dispenses the monomer/crystal slurry into the substrate cups via an ultrasonic atomizer. The atomizer ensures that the slurry deposits evenly over the bottom of the cup. A $25-\mathrm{kHz}$ atomizer was chosen to ensure even dispersal of all crystal sizes, from $75 \mu \mathrm{m}$ and smaller. Each time a substrate cup was positioned under the atomizer, a stepping motor drove the nozzle to the correct position above the cup bottom, a solenoid valve opened for a pre-set interval to dispense the slurry, and the nozzle was retracted.

\section{VACUUM CHAMBER}

The vacuum chamber was converted from an existing rf diode sputtering system. It was a 30 -in.-diameter cylinder, 12-in. thick. It was modified to contain the carousel and to mount the other subsystems to its exterior. The chamber was pumped with a mechanical, rough vacuum pump and operated at about 50-millitorr pressure. 



\section{SUBSTRATE CAROUSEL}

The carousel was driven by a stepping motor. It held nine cups that were repeatedly positioned under the atomizer to be filled, then placed under the ultraviolet (UV) source to be cured.

\section{ULTRAVIOLET LIGHT SOURCE}

The UV light was mounted on top of the vacuum chamber and irradiated the slurry through a fused quartz window. The deuterium discharge light was operated in continuous mode and delivered approximately 1800 watts distributed over the UV, visible, and near-IR regions of the spectrum.

\section{COMPUTER CONTROL SYSTEM}

A personal computer (PC) compatible system was used to control the sequencing of all processing steps. The software employed was written in-house in Visual Basic 2.0 and run under Windows 3.1. The interface to the equipment consisted of two parts: an RS-232 port to a Compumotor $\mathbf{4 0 0 0}$ stepping motor indexer; and a DT2812, backplane installed, analog and digits $\mathrm{L} O \mathrm{O}$ data acquisition card. The indexer controlled the carousel and atomizer motions. The DT2812 read temperatures and pressures, sensed atomizer and carousel positions via optical interrupters, opened and closed the dispense solenoid, controlled the syringe pump air pressure, and turned the UV light on and off. A graphical interface permitted the operator to control the cups would be used, the amount of slurry to dispense, the syringe pump pressure, the length of UV exposure, the number of layers, the carousel speed, the dispense-height above the cup bottom, and many other aspects of the process.

The system met operational requirements and was reliable enough to be set up under computer supervision and left to run overnight unattended. 


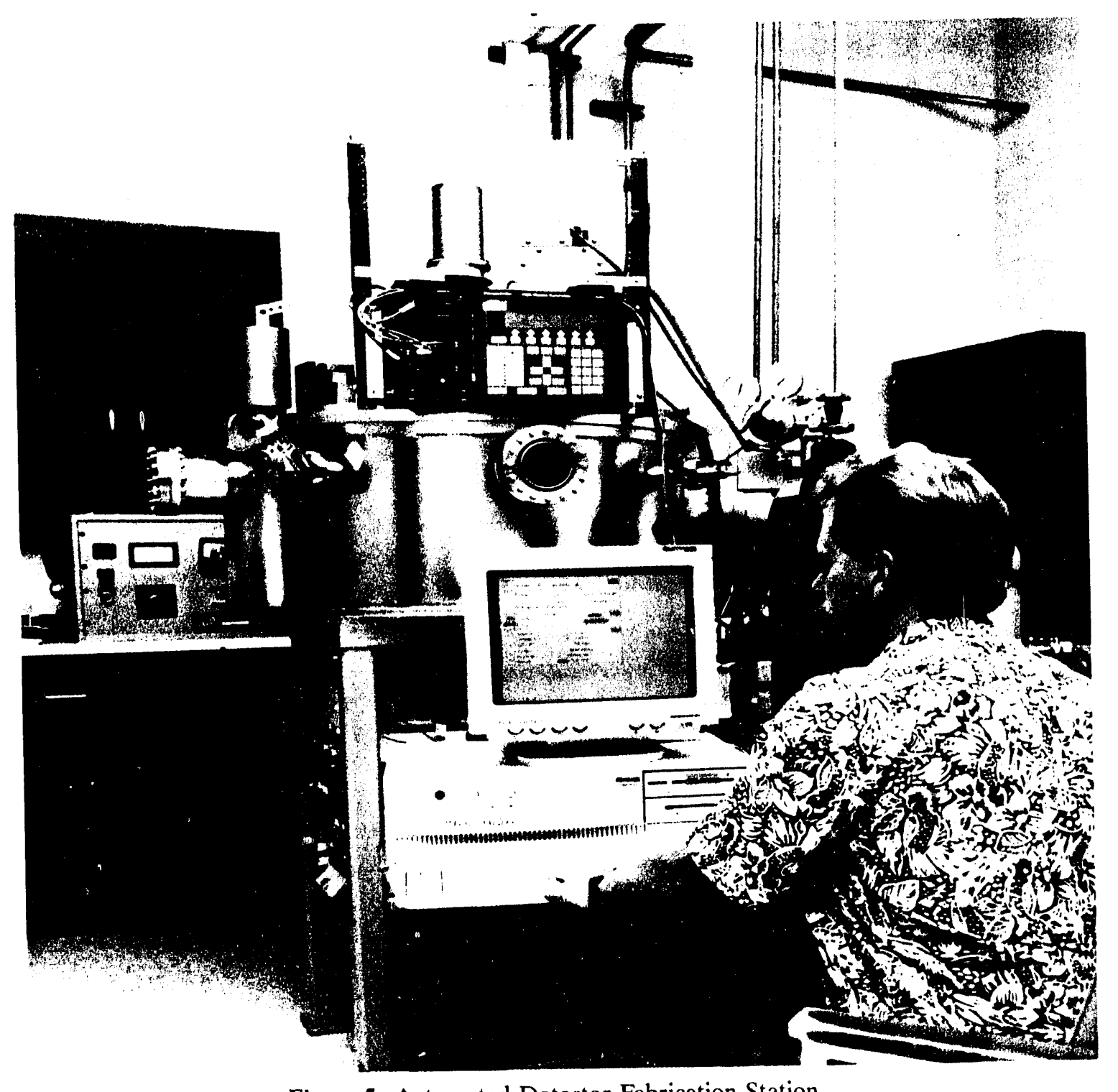

Figure 5. Automated Detector Fabrication Station 


\section{DESCRIPTION OF PROTOTYPE FAST NEUTRON DETECTION INSTRUMENT}

Based on the development of the new scintillating material, a hand-held neutron detection instrument has been designed at PNL. Because the proposed detector is fabricated from inorganic salts in an inert plastic, the detector is very simple, rugged, inexpensive, and well suited to rough field conditions. Moreover, because the instrument is able to reject gamma rays intrinsically based only on pulse height, it is simpler in conception than liquid scintillation neutron detectors that rely on more com licated pulse-timing rejection. Thus, the instrument can be lightweight, battery-operated, and rugged, i.e., suitable for a range of field conditions.

The prototype neutron instrument, illustrated in Figure 6, is designed to accommodate a 2- to 3-in. neutron scintillator detector with the provision for adding a thermal neutron and/or gamma detector, as required. The detector is hand-held, weighs than $4 \mathrm{lb}$, and can operate for 8 to 12 hours on a rechargeable battery pack. A possible application of the detector is illustrated in Figure 7. In this application, the user could obtain the instrument from a wall charger and use the detector to survey a truck for the presence of fast neutrons.

Different design cutaways are located in the Appendix. In the present design, a small board contains the preamplifier and amplifier on a single board. A 2-in. photomultiplier tube is powered using a CockroftWalton high voltage generator. A small multichannel analyzer receives the amplified signals and the spectrum is then displayed. A microprocessor on a board rounds out the capability of the instrument and provides for a degree of data reduction within the instrument.

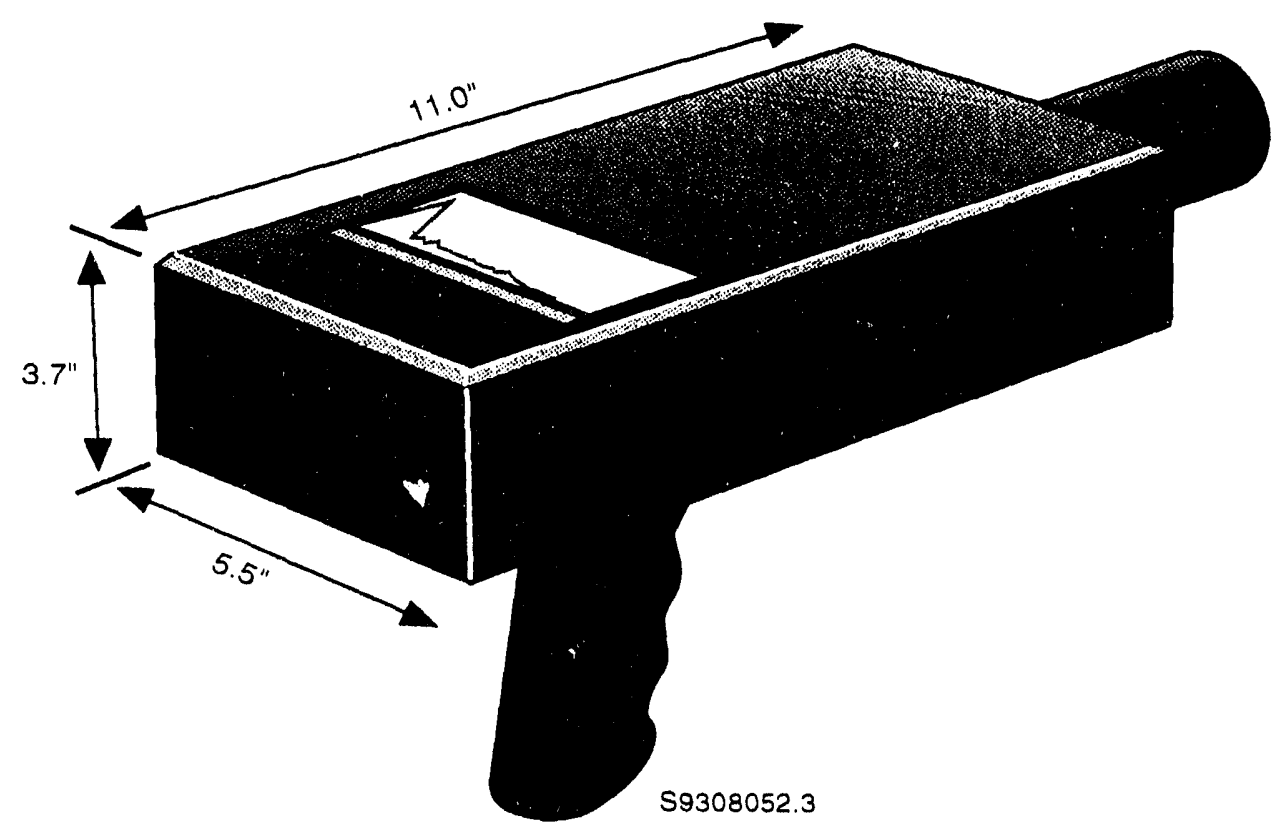

Figure 6. Scintillator Applications (ST862) Prototype Neutron Detector 

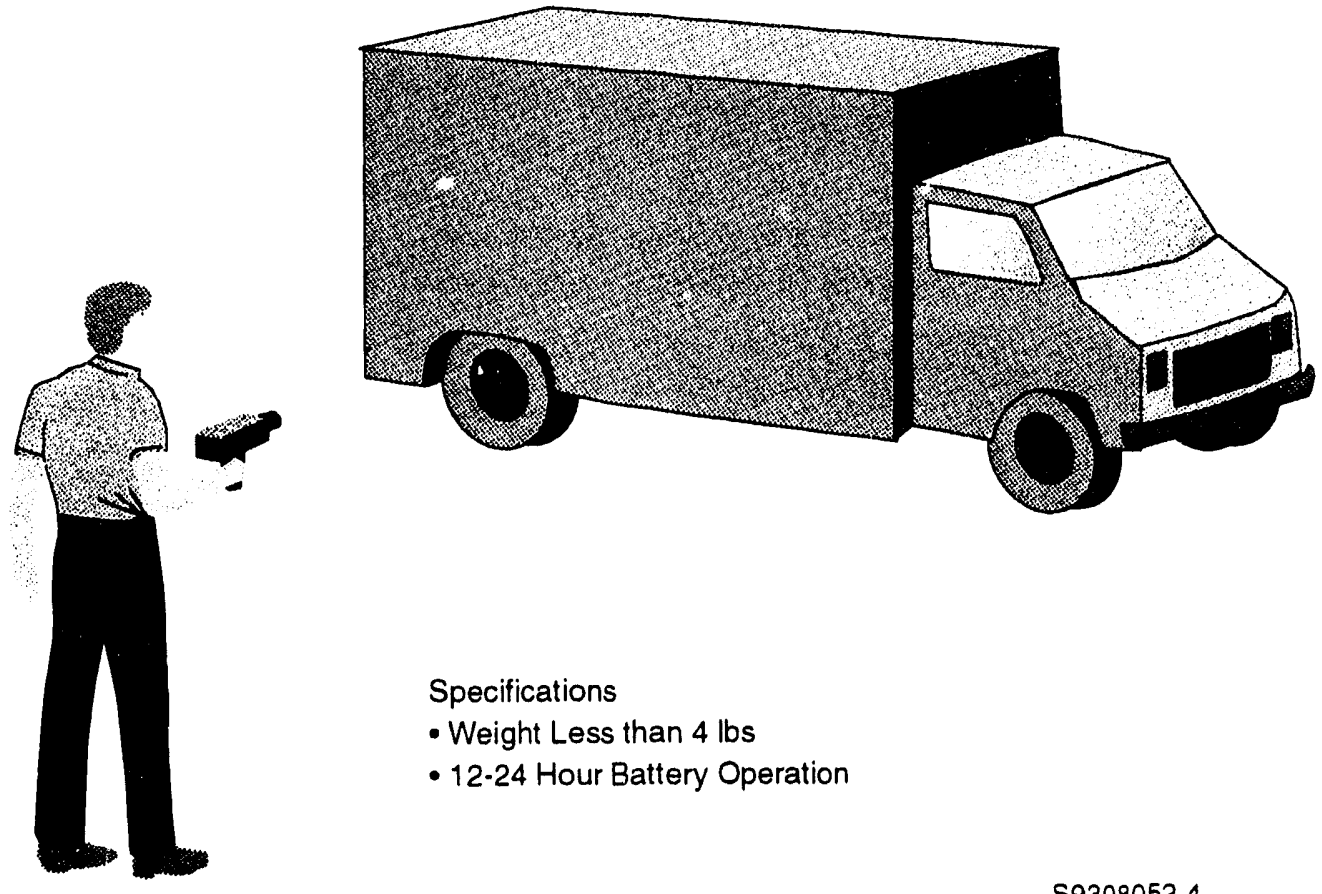

Specifications

- Weight Less than 4 lbs

- 12.24 Hour Battery Operation

S9308052.4

Figure 7. Scintillator Applications (ST862) Prototype Detector Hand-held Inspection Instrument 
APPENDIX

•

- 


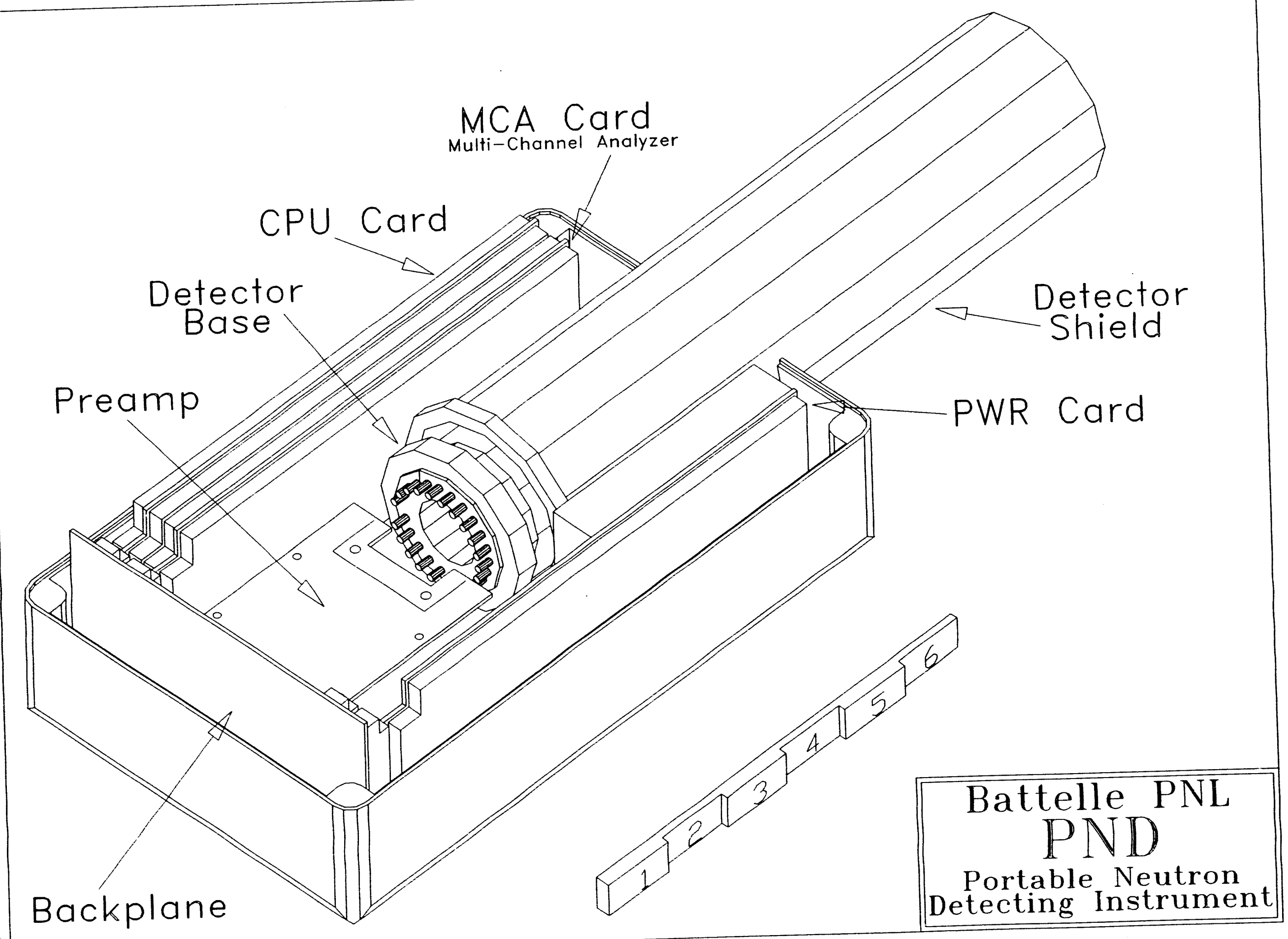




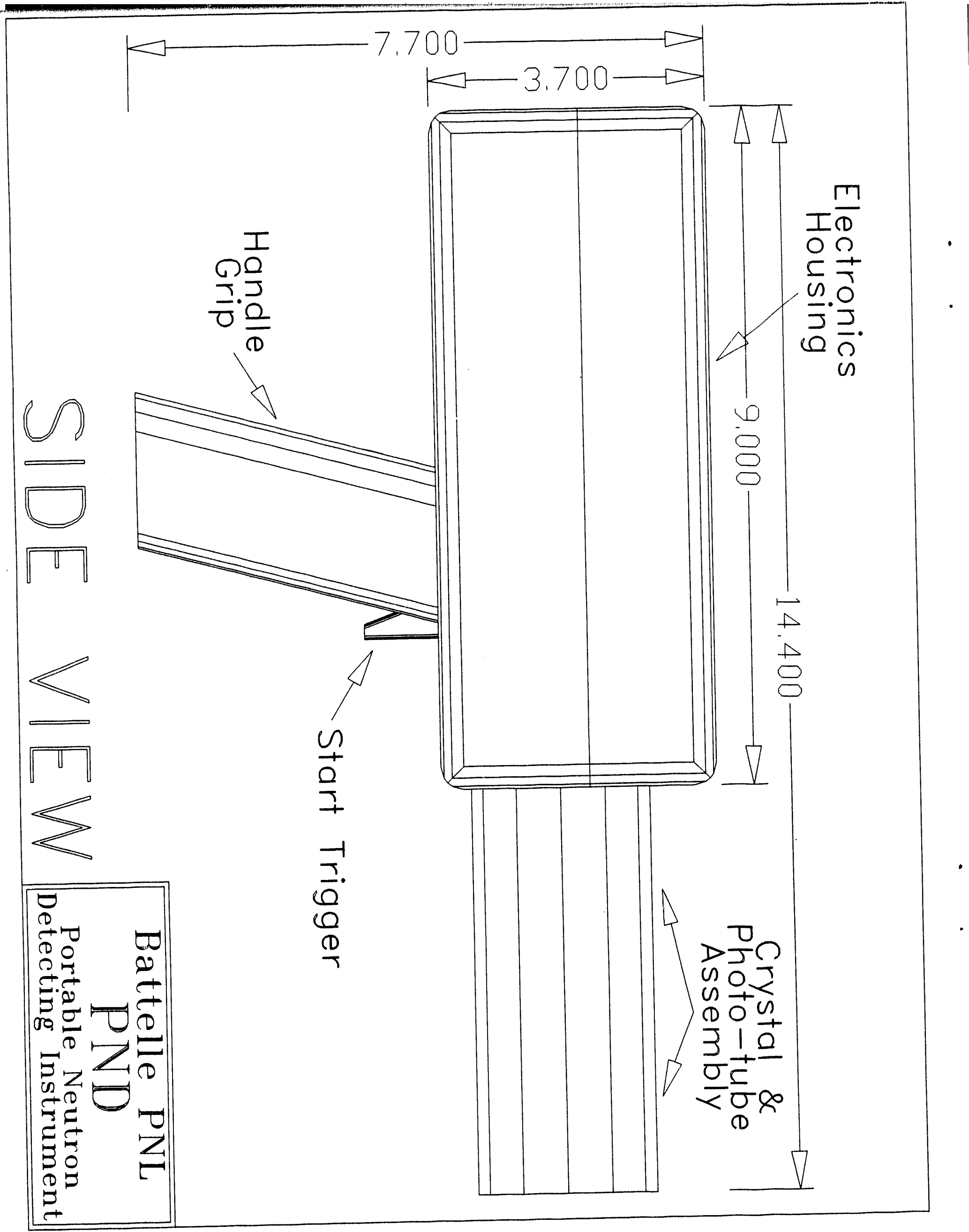




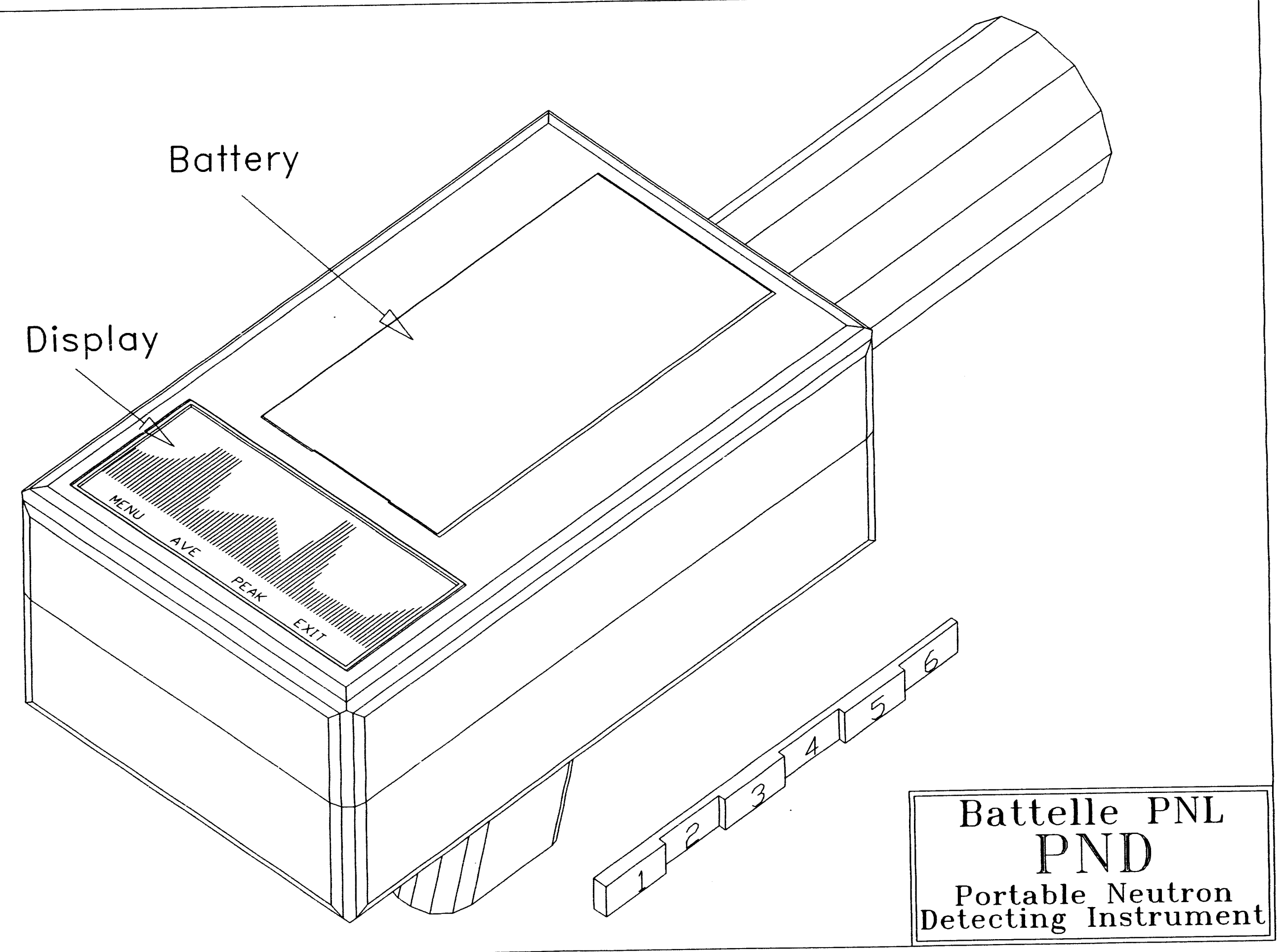




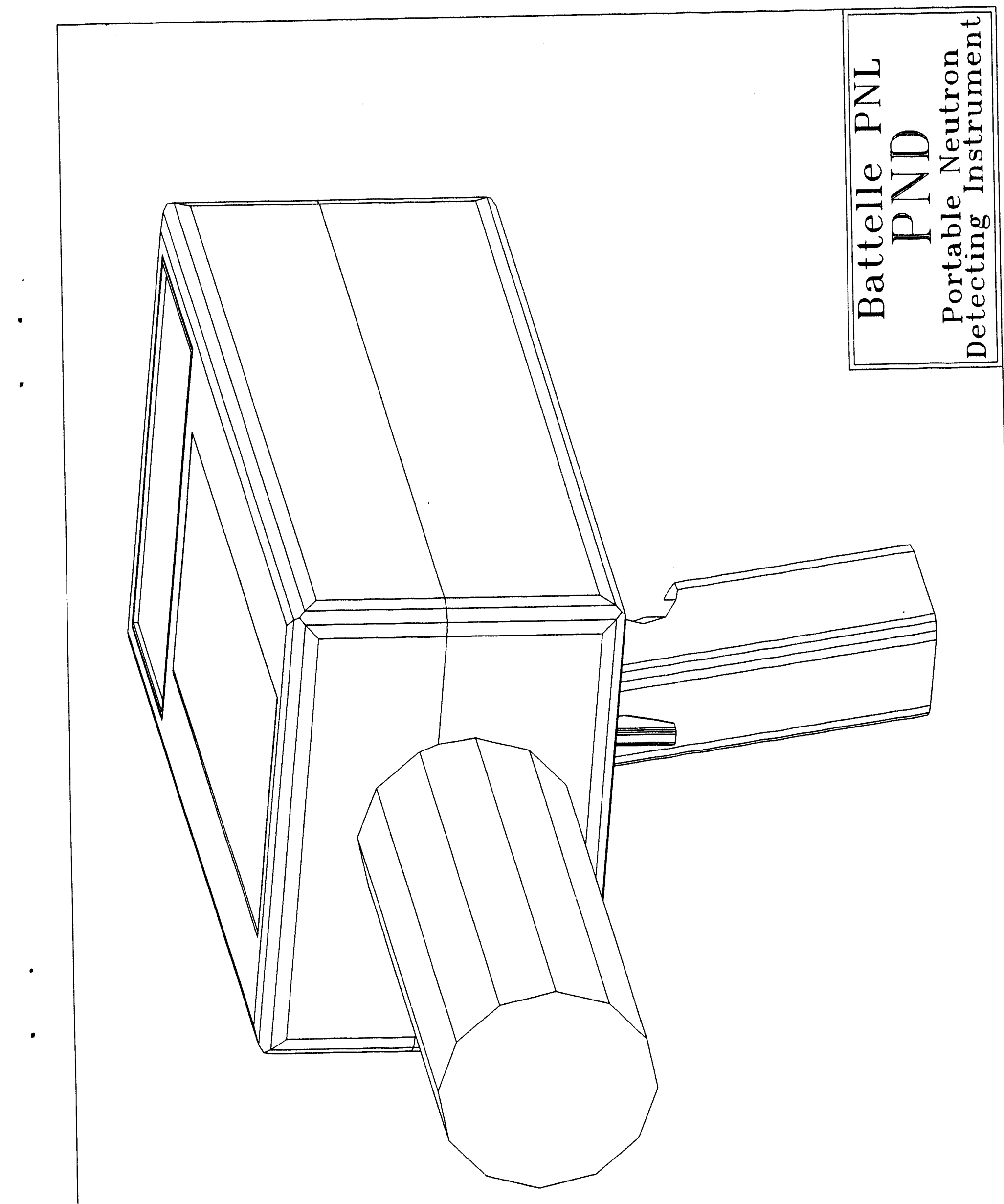




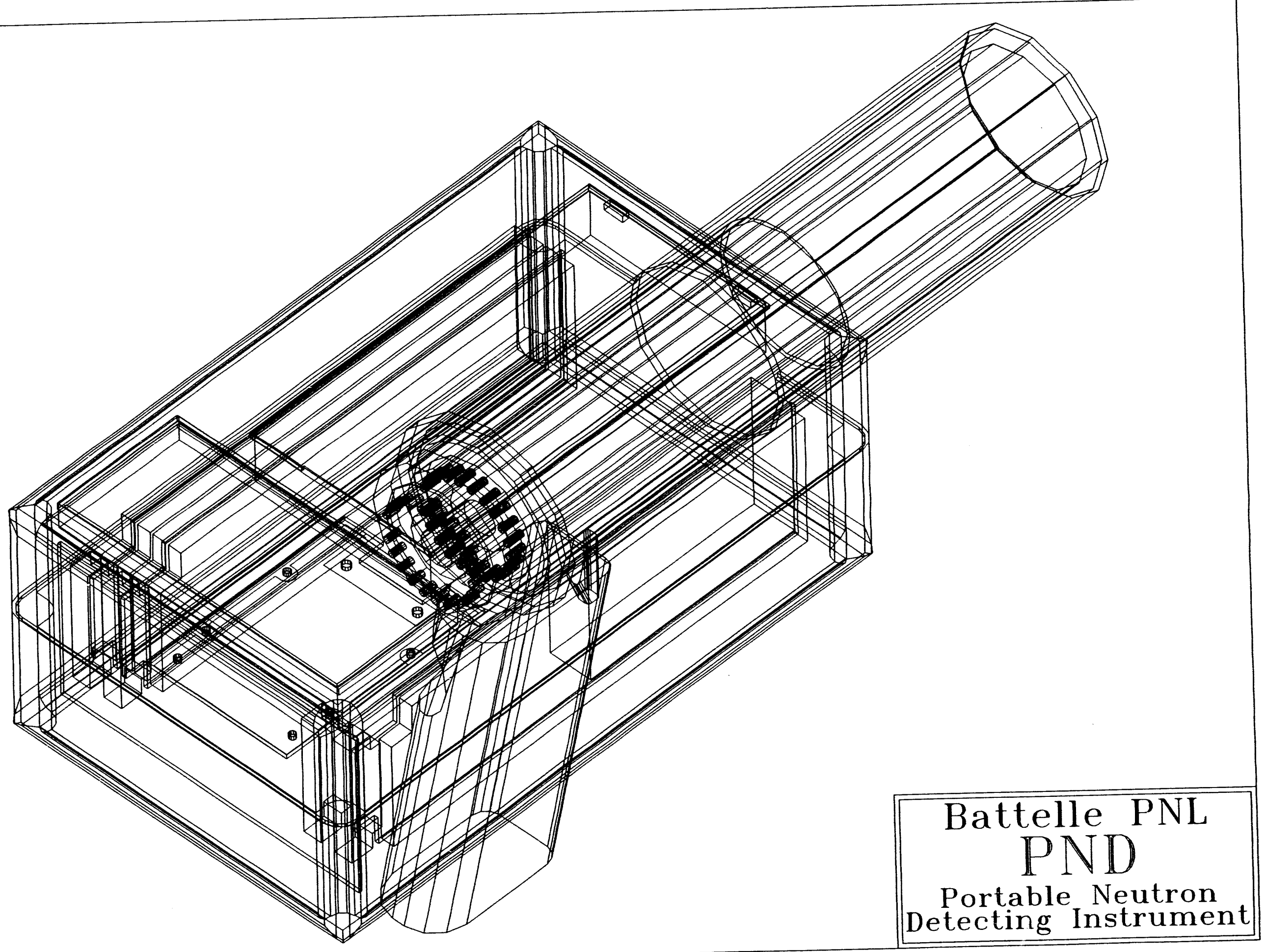




\section{DISTRIBUTION}

No. of

Copies

OFFSITE

2 Office of Scientific and Technical Information

\section{ONSITE}

17 Pacific Northwest Laboratory

J. D. Affinto

S. D. Miller (8)

K. L. Soldat

D. R. Sisk

Publishing Coordination

Technical Report File (5)

Distr.1 

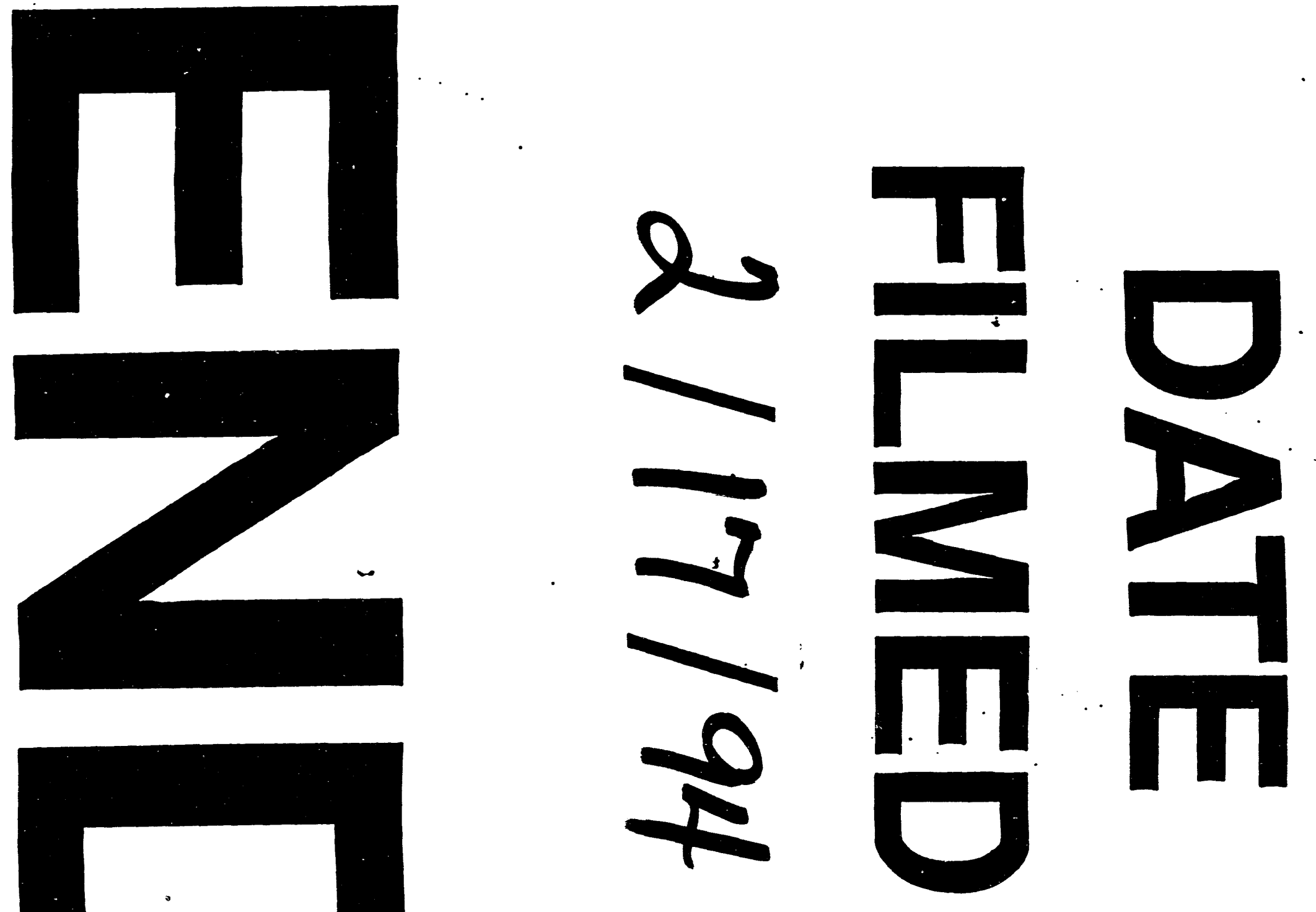
